$$
\text { CONF- } 9100994--4
$$

To be Presented at the:

Tenth International Conference on Ion Beam Modification of Materials (IBMM-96)

Albuquerque, NM, September 1-6, 1996

Proceeding will be Published in:

Section B of Nuclear Instruments and Methods in Physics Research

\title{
Optically Active Surfaces Formed by Ion Implantation and Thermal Treatment
}

Laurence A. Gea, Lynn A. Boatner, Heather M. Evansł, and Ray Zuhr

Solid State Division, Oak Ridge National Laboratory, Oak Ridge, TN 37831-6056 (USA)

August 1996

\begin{abstract}
'The submitted manuscript has been authored by a contractor of the U.S. Government under contract No. DEAC05-96OR22464. Accordingly, the U.S. Government retains a nonexclusive, royalty-free license to publish or reproduce the published form of this contribution, or allow others to do so, for U.S. Government purposes."
\end{abstract}

prepared by

Solid State Division

Oak Ridge National Laboratory

P.O. Box 2008

Oak Ridge, Tennessee 37831-6056

managed by

LOCKHEED MARTIN ENERGY RESEARCH CORP.

for the

under contract DE-AC05-96OR22464 


\section{DISCLADMER}

Portions of this document may be illegible in electronic image products. Images are produced from the best available original document. 
Ref. \#233

\section{OPTICALLY ACTIVE SURFACES FORMED BY ION IMPLANTATION AND THERMAL TREATMENT}

Laurence A. Gea, Lynn A. Boatner, Heather M. Evans $\ddagger$, and Ray Zuhr Solid State Division, Oak Ridge National Laboratory, Oak Ridge, TN 37831-6056 USA

Abstract

Embedded $\mathrm{VO}_{2}$ precipitates have been formed in single-crystal sapphire by the ion co-implantation of vanadium and oxygen and subsequent thermal annealing. The embedded $\mathrm{VO}_{2}$ particles have been shown to exhibit an optical switching behavior that is comparable to that of continuous thin films. In this work, the mechanisms of formation of these optically active particles are investigated. It is shown that precipitation of the vanadium dioxide phase is favored when the thermal treatment is performed on an ion-damaged but still crystalline (rather than amorphized) $\mathrm{Al}_{2} \mathrm{O}_{3}$ substrate. The best optical switching behavior is observed in this case, and this behavior is apparently correlated with a more-favorable dispersion of $\mathrm{VO}_{2}$ small particles inside the matrix.

‡ Great Lakes Colleges Association/Associated Colleges of the Midwest, participant from Macalester College, St. Paul, MN.

Contact Author:

Laurence A. Gea

Oak Ridge Nat'l Lab

P. O. Box 2008, MS-6056

Oak Ridge, TN 37831-6056

Phone: (423) 574-5495, Fax: (423) 574-4814

email: lgea@solid.ssd.ornl.gov 
Recent results have established that it is possible to form crystallographically coherent vanadium dioxide precipitates that are embedded in single-crystal sapphire by the ion co-implantation of vanadium and oxygen followed by an appropriate thermal treatment (1). Vanadium dioxide exhibits a reversible phase transition (2) from a semiconductor (monoclinic structure) to a metal (tetragonal structure) upon heating above a transition temperature of about $70^{\circ} \mathrm{C}$. The phase transition of the embedded $\mathrm{VO}_{2}$-precipitate phase was monitored using infra-red transmission measurements as a function of temperature. The curve obtained on heating exhibits decreasing optical transmission during the transition to the opaque metallic state of $\mathrm{VO}_{2}$ and, on cooling, exhibits an increasing optical transmission in returning to the transparent semi-conducting state. These transitions occur at two different temperatures (exhibiting hysteresis), in agreement with the behavior observed for both thin films and single crystals of $\mathrm{VO}_{2}$. However, differences were observed in the maximum transmission change $\Delta$, the sharpness of the transition $S$ (the temperature range necessary for the complete optical switching), and the transition temperature $T_{C}$. The aim of the present work is to provide a basis for understanding the observed anomalies between the ion-implantation-produced $\mathrm{VO}_{2}$ precipitates and either thin-film or bulk $\mathrm{VO}_{2}$.

In order to understand the role played by various parameters (e.g., the precipitate size, thermal stresses, or oxygen content) on the characteristics of the hysteresis (i.e., $\Delta, S$, and $T_{C}$ ) it was necessary to first investigate the more-basic mechanisms that lead to the precipitation of such a phase. For this purpose, c-axisoriented sapphire specimens were implanted with 2 to $20 \times 10^{16} \mathrm{~V}$ ions $\cdot \mathrm{cm}^{-2}$ at 
$300 \mathrm{~K}$ and $77 \mathrm{~K}$ and subjected to a $10 \mathrm{~min}$. thermal treatment in pure flowing argon at temperatures ranging from 500 to $1000^{\circ} \mathrm{C}$. Stoichiometric co-implantation of oxygen was performed on all the samples prior to the thermal treatment, since the presence of oxygen was shown to enhance the optical-switching properties, in agreement with previous findings concerning the growth of thin films of $\mathrm{VO}_{2}$ deposited on sapphire $(3,4)$. Characterization of the microstructures was carried out by means of X-ray diffraction (XRD) measurements and Rutherford Backscattering Spectroscopy (RBS) in the channeling geometry. Optical transmission measurements were made using an IR spectrophotometer (wavelength fixed at 3.4 $\mu \mathrm{m})$ equipped with a heating stage.

Optical-switching curves for precipitates of $\mathrm{VO}_{2}$ embedded in $\alpha-\mathrm{Al}_{2} \mathrm{O}_{3}$.

Figure 1 shows the optical transmission of a sapphire specimen implanted with vanadium $\left(2 \times 10^{17} \mathrm{~V}\right.$ ions $\left.\cdot \mathrm{cm}^{-2}\right)$ and oxygen $\left(4.10^{17} \mathrm{O}\right.$ ions $\left.\cdot \mathrm{cm}^{-2}\right)$ and annealed at $900^{\circ} \mathrm{C}$. As the temperature is scanned between 30 and $90^{\circ} \mathrm{C}$, the transmission change for the precipitate system is somewhat smaller $(\Delta=55 \%)$ than that of a continuous thin film of $\mathrm{VO}_{2}$ taken as a reference $(\Delta \sim 100 \%)$. It should be noted here that $\Delta$ is different from the optical contrast used previously by various authors to describe the optical-switching quality of thin films. In the present case, $\Delta$ is defined as the difference between the optical transmission at $30^{\circ} \mathrm{C}$ and the transmission at $90^{\circ} \mathrm{C}$, normaiized to the room-temperature transmission: $\Delta=\left(\operatorname{Tr}_{30}-\operatorname{Tr}_{90}\right) / \operatorname{Tr}_{30}$. The 
change in optical transmission of $\mathrm{VO}_{2}$ with temperature is primarily governed by the switching of individual domains or grains (5) and, in the case of the present $\mathrm{VO}_{2} / \mathrm{Al}_{2} \mathrm{O}_{3}$ ranocomposite system, the transmission change is, therefore, mainly dependent on the number of precipitates. In fact, $\Delta$ can provide a measure of the surface coverage of the precipitates as a first approximation, e.g., the surface coverage would be approximately $55 \%$ in the case of the $2 \times 10^{17} \mathrm{~V}$ ions $\cdot \mathrm{cm}^{-2}$ implant.

As can also be seen in Figure 1, the sharpness of the transition (i.e., $\sim 20$ degrees) is about five times that observed for a $\mathrm{VO}_{2}$ thin film, indicating that extra energy is required to overcome barriers to the propagation of the crystallographic shear in the case of embedded $\mathrm{VO}_{2}$ precipitates - particularly in the hightemperature region.

Finally, regarding the transition temperature, the switching transition occurs at a temperature that is 4 to 10 degrees higher than that reported for the best thin films of $\mathrm{VO}_{2}(6)$. Possible candidates for this difference between the embedded precipitates and $\mathrm{VO}_{2}$ thin films are: high thermal stresses due to process temperature of $900-1000^{\circ} \mathrm{C}$ for $\mathrm{VO}_{2}$ precipitates as compared to $500-600^{\circ} \mathrm{C}$ for thin films, $\mathrm{Al}$ impurities introduced into the precipitates by the $\mathrm{Al}_{2} \mathrm{O}_{3}$ matrix, and particle-size effects.

The microstructure of the $\mathrm{VO}_{2}$ precipitate $/ \mathrm{Al}_{2} \mathrm{O}_{3}$ host system at room temperature, as determined by X-Ray diffraction using a four-circle diffractometer, was found to be very close to the structure described in the JCPDS 9-142 file (7) but with an indication of some distortions (8). In the case of high-dose ion implantation, the $\mathrm{VO}_{2}$ precipitates were several microns long (as measured in the 
case where the precipitates were near the surface), and they were threedimensionaliy crystallographically oriented with respect to the sapphire substrate (3). A coherence length of only $50 \mathrm{~nm}$ for the $\mathrm{VO}_{2}$ phase at room temperature was deduced, however (8). These results indicate that the "50 $\mathrm{nm}$ domains" are not dispersed inside the matrix but rather that they are segregated to form long, flat oriented precipitates that are easily detected with an optical microscope. The microstructure and dispersion of the $\mathrm{VO}_{2}$ phase are certainly of primary importance for understanding the anomalies observed in the hysteretic behavior of the $\mathrm{VO}_{2}$ precipitate $/ \mathrm{Al}_{2} \mathrm{O}_{3}$ host system.

Mechanisms of formation of the $\mathrm{VO}_{2} / \mathrm{Al}_{2} \mathrm{O}_{3}$ composite surface: Formation of the embedded switching phase.

Figure 2 shows the normalized transmission change $\Delta$ as a function of the annealing temperature for several $\mathrm{Al}_{2} \mathrm{O}_{3}$ single-crystal samples co-implanted with vanadium and oxygen at various energies and doses. In the three cases: high dose implantation at $300 \mathrm{~K}$ (curve 2a), low dose implantation at $300 \mathrm{~K}$ (curve $2 \mathrm{~b}$ ), and low-dose implantation at $77 \mathrm{~K}$ (curve $\mathrm{c}$ ), the evolution of the transmission change $\Delta$ (which is assumed in a first approximation to be proportionnal to the number of "switchable" $\mathrm{VO}_{2}$ precipitates) is similar. The precipitates start to form between $600^{\circ} \mathrm{C}$ and $800^{\circ} \mathrm{C}$ (region I) and only a partial transmission change is observed. In the $800-900^{\circ} \mathrm{C}$ range (region II), the transmission change is a maximum, and finally at 
$1000^{\circ} \mathrm{C}$ (30 min. anneal), $\Delta$ drops dramatically indicating a nearly complete loss of optical switching (region III).

The fact that $\mathrm{VO}_{2}$ precipitates are formed between $600^{\circ} \mathrm{C}$ and $700^{\circ} \mathrm{C}$ (for a dose of $2 \times 10^{17} \mathrm{~V}$ ions $\cdot \mathrm{cm}^{-2}$ at room temperature) is surprising since, in the case of $\mathrm{Al}_{2} \mathrm{O}_{3}$, temperatures higher than $800^{\circ} \mathrm{C}$ are required for the recovery of the ion-damaged lattice to occur (9). This would indicate that vanadium is highly mobile in $\mathrm{Al}_{2} \mathrm{O}_{3}$ and that the precipitation of $\mathrm{VO}_{2}$ is somehow independent on the crystalline state of the substrate. The minimum temperature required for the nucleation of the $\mathrm{VO}_{2}$ phase, however, is higher for lower implant doses (curve 2b) and suggests either that a threshold value exists for the vanadium concentration (e.g., the lower the local concentration, the greater the path leading to precipitation) or that a minimum size for the "switchable" $\mathrm{VO}_{2}$ domain needs to be exceeded for optical switching to occur within the limits of detection.

A comparison of the curves shown in Figs. $2 b$ and $2 c$ (corresponding to a similar dose of $5 \times 10^{16} \mathrm{~V}$ ions $\cdot \mathrm{cm}^{-2}$ ) suggests that the local concentration in the asimplanted state is certainly not a sufficient factor: i.e., a temperature larger than $800^{\circ} \mathrm{C}$ is required for the precipitates to form in the case of the implant made at $77 \mathrm{~K}$ (curve 2c); while in the case of the $300 \mathrm{~K}$ implantation, precipitates are present below $800^{\circ} \mathrm{C}$ (curve $2 \mathrm{~b}$ ). The mechanisms of the sapphire recovery from displacive ion damage can play a major role in the redistribution of the implanted vanadium. In fact, these mechanisms have been shown (9) to depend on the amount of damage in the as-implanted state (amorphization at $77 \mathrm{~K}$ and high damage at $300 \mathrm{~K}$ ), and this effect is illustrated in Figure 3. In this figure, the RBS spectra of the specimens 
implanted at $77 \mathrm{~K}$ (curve $3 \mathrm{a}$ ) and $300 \mathrm{~K}$ (curve $3 \mathrm{~b}$ ) and annealed at $900^{\circ} \mathrm{C}$ are shown in both the random and channeling geometry. For the case of the liquid nitrogen temperature implantation, the substitution fraction is close to $100 \%$ and the sapphire lattice is nearly completely recrystallized. Furthermore, the depth distribution of the vanadium is larger than in the as-implanted state (not shown), while for the room-temperature implantation, it is narrower. The diffusion coefficient of vanadium in amorphized $\mathrm{Al}_{2} \mathrm{O}_{3}$ is probably lower than that in the damaged but still crystalline form. The migration and incorporation of $\mathrm{V}$ is then governed by the movement of the recrystallization front (9). In the case of the damaged $\mathrm{Al}_{2} \mathrm{O}_{3}$ crystalline state, the high mobility of vanadium (in conjunction with a favorable annealing atmosphere) allows the nucleation and growth of the $\mathrm{VO}_{2}$ precipitates in a more "independent" manner in the vicinity of the the damage peak. These results also suggest that the diffusion of vanadium in $\mathrm{Al}_{2} \mathrm{O}_{3}$ occurs with the help of some lattice defect: e.g., a dislocation or aluminum vacancy. As a consequence, the $\mathrm{VO}_{2}$ precipitates formed at room temperature are expected to be larger (or at least to cover a larger area since the in-depth distribution is narrower). From the RBS measurements, the depth distribution of $\mathrm{VO}_{2}$ for the $77 \mathrm{~K}$ implant is estimated to be twice that of the $300 \mathrm{~K}$ implant. If one assumes that the same amount of $\mathrm{VO}_{2}$ is formed in both cases, it is possible to estimate the surface coverage for the $77 \mathrm{~K}$ implantation to be half that of the $300 \mathrm{~K}$ implant. From Figure 2, the value of $\Delta$ for the liquid-nitrogen temperature implant $(6 \%)$ is about half that of the room-temperature implant $(15 \%)$ - as expected. Although the values for $\Delta$ are small for these low doses, the difference between the two cases is larger than the $3 \%$ 
estimated error. Measurements of the surface coverage by TEM should be carried out, however, to confirm this interpretation.

As far as region III is concerned, the loss of optical switching activity is related to the diffusive loss of precipitates at the surface as detected by optical microscopy. The reason for such an instability will be treated in detail in a subsequent paper.

In summary, the most efficient optical-switching behavior has been observed in implanted $\mathrm{Al}_{2} \mathrm{O}_{3}$ samples that were not amorphized during the implantation process. The as-implanted damage state determines the nature of the recovery processes of the $\mathrm{Al}_{2} \mathrm{O}_{3}$ lattice as well as the diffusion mechanisms for the implanted vanadium. The superior optical switching observed for the room temperature implants is believed to be related to the larger in-plane size of the precipitates and other characterization methods are currently being applied in order to verify the proposed mechanism. This research was sponsored by the Division of Materials Sciences, U.S. Department of Energy under Contract No. DE-AC05-96OR22464 with Lockheed Martin Energy Research Corp.

\section{REFERENCES:}

(1) L. A. Gea and L. A. Boatner, Appl. Phys. Lett. 68 (1996) 3381.

(2) F.J. Morin, Phys. Rev. Lett. 3 (1959) 34.

(3) L. A. Gea, L. A. Boatner, J. D. Budai, and R. A. Zuhr, in: Ion-Solid Interactions for Materials Modification and Processing, ed D. B. Poker et al, (Materials Research Society Symposium Proceedings, 1996) 215.

(4) F.C. Case, J. Vac. Sci. Technol. A7 (1989) 1194.

(5) J. F. De Natale, P.J. Hood, and A. B. Barker, J. Appl. Phys. 66 (1989) 5844.

(6) F.C. Case, J. Vac. Sci. Technol. A2 (1984) 1509.

(7) JCPDS, International Center for Diffraction Data, 1601 Park Lane, Swarthmore, PA.

(8) L. A. Gea, L. A. Boatner, J. D. Budai, and R. A. Zuhr, to be published.

(9) C. W. White, C. J. McHargue, P. S. Sklad, L. A. Boatner, and G. C. Farlow, Mat. Sci. Rep. 4 (1989) 41-146. 


\section{FIGURE CAPTIONS}

FIGURE 1: Optical transmission spectrum at a fixed wavelength $(3.4 \mu)$ showing the characteristic hysteretic $\mathrm{VO}_{2}$ phase transition for:

(a) $\mathrm{VO}_{2}$ precipitates formed in $\mathrm{Al}_{2} \mathrm{O}_{3}$ co-implanted with $\mathrm{V}$ and $\mathrm{O}$ and thermally annealed; (b) a standard thin film of $\mathrm{VO}_{2}$ deposited on $\mathrm{Al}_{2} \mathrm{O}_{3}$ [1].

FIGURE 2: Maximum optical transmission change $\Delta$ as a function of annealing temperature for single-crystal $\mathrm{Al}_{2} \mathrm{O}_{3}$ co-implanted with vanadium and oxygen at:
(a) $2 \times 10^{17} \mathrm{~V}$ ions $\cdot \mathrm{cm}^{-2}$ at $300 \mathrm{~K}$
(b) $5 \times 10^{16} \mathrm{~V}$ ions $\cdot \mathrm{cm}^{-2}$ at $77 \mathrm{~K}$
(c) $5 \times 10^{16} \mathrm{~V}$ ions $\cdot \mathrm{cm}^{-2}$ at $300 \mathrm{~K}$

FIGURE 3: RBS spectra of sapphire co-implanted with vanadium $\left(5 \times 10^{16} \mathrm{~V}\right.$ ions $\left.\cdot \mathrm{cm}^{-2}\right)$ and oxygen and annealed in pure $\mathrm{Ar}$ at $900^{\circ} \mathrm{C}$ for $10 \mathrm{~min}$;
(a) implantation performed at $300 \mathrm{~K}$
(b) implantation performed at $77 \mathrm{~K}$ 


\section{Figure 1}

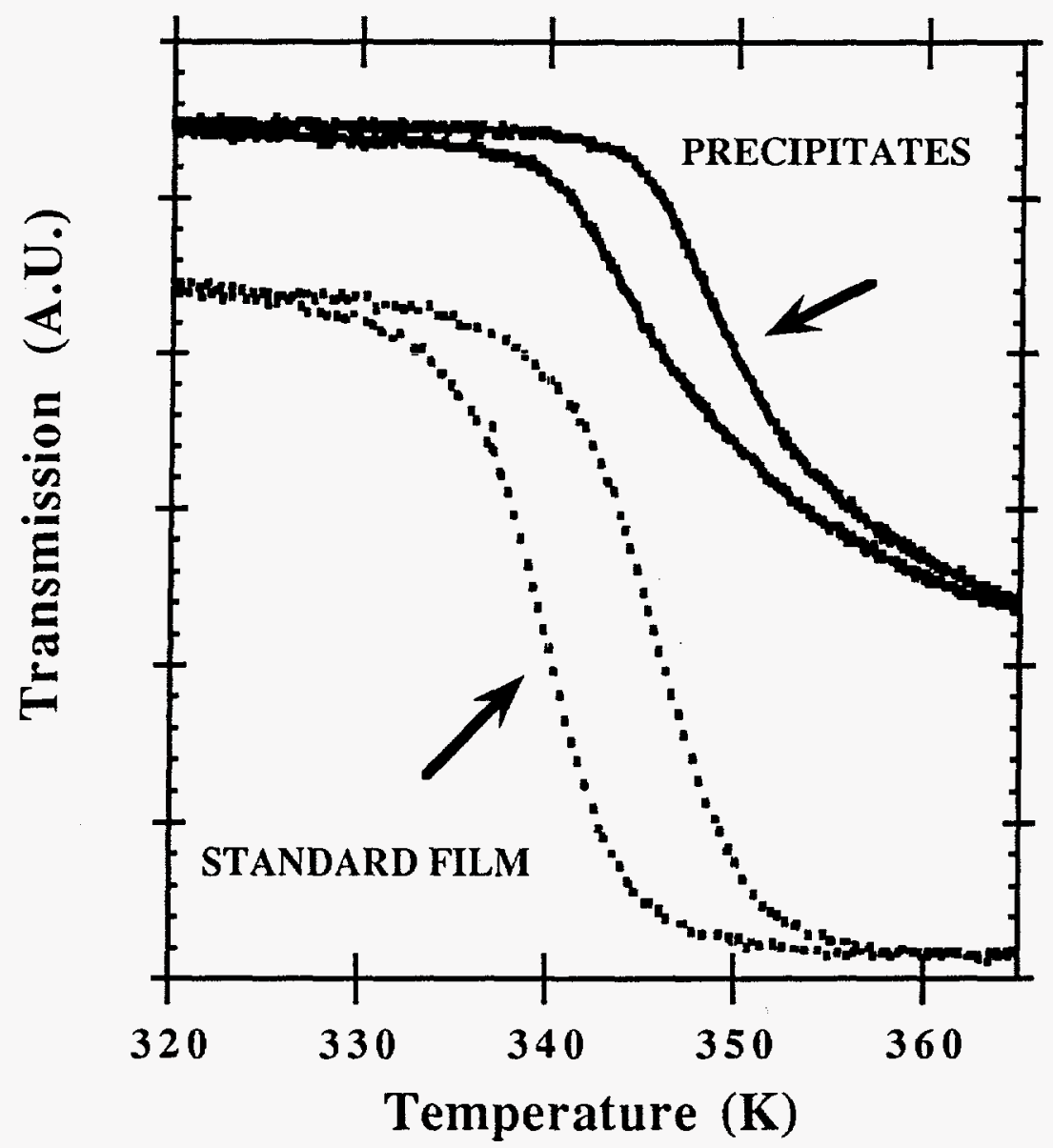




\section{Figure 2}

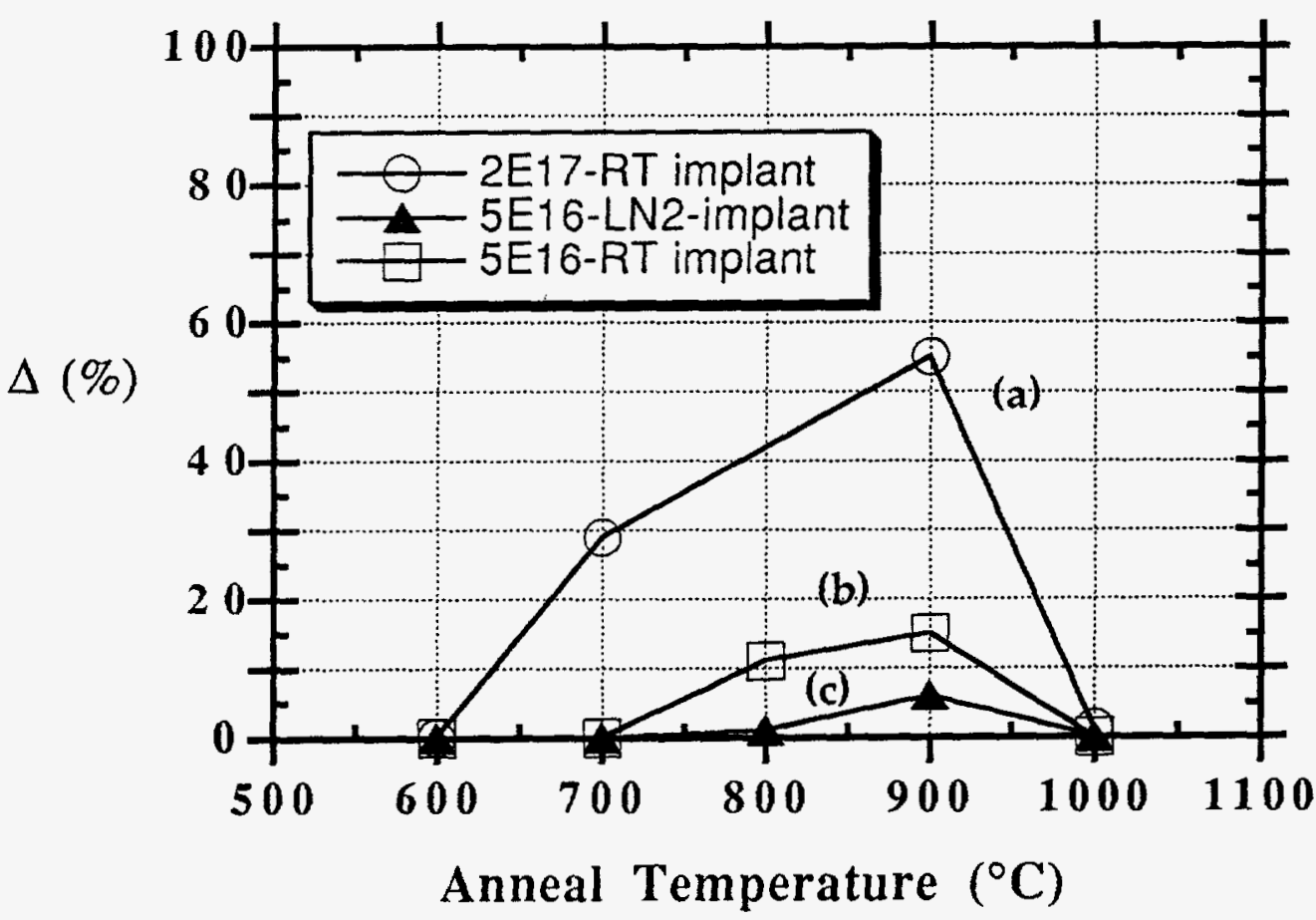




\section{Figure 3}
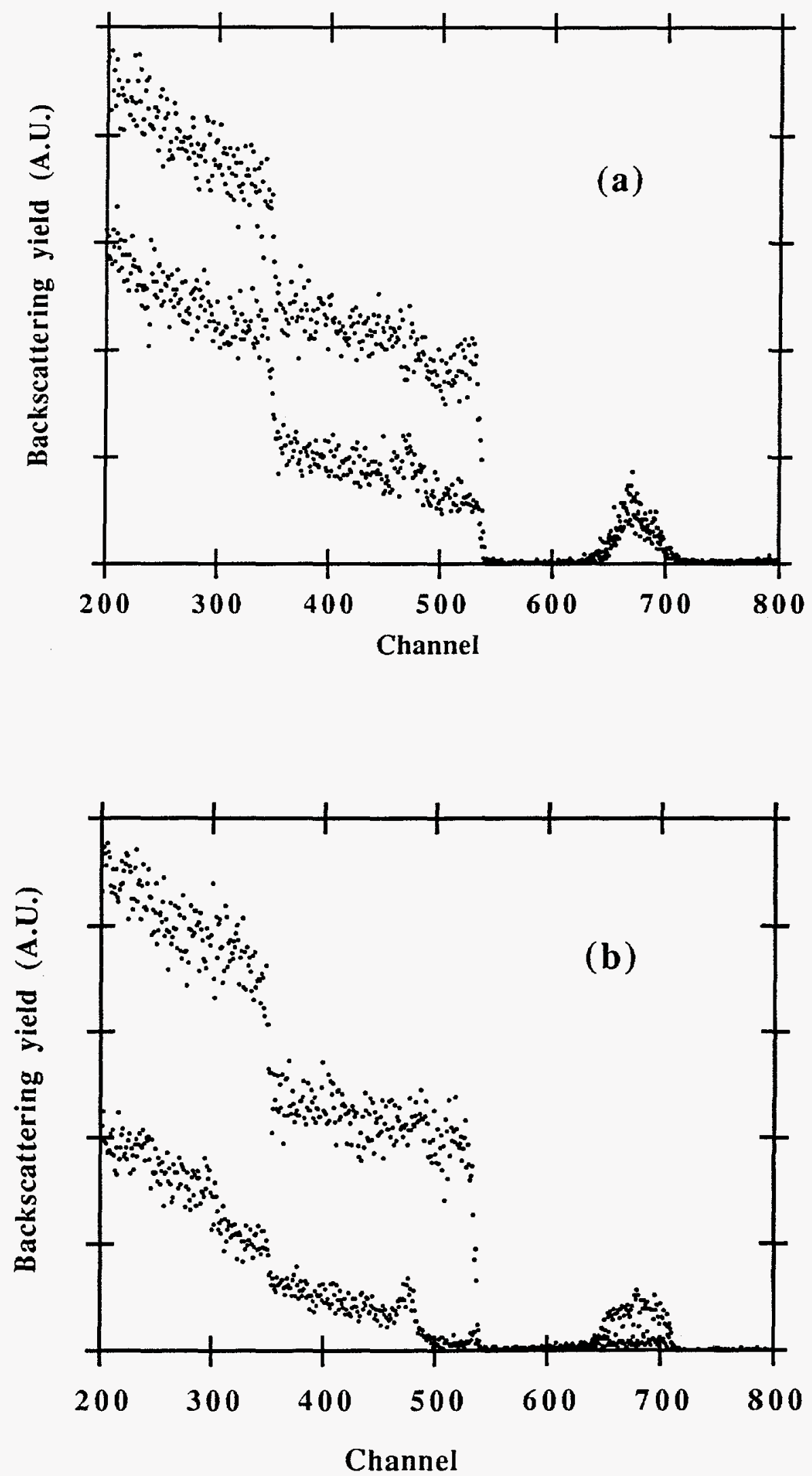


\section{DISCLAIMER}

This report was prepared as an account of work sponsored by an agency of the United States Government. Neither the United States Government nor any agency thereof, nor any of their employees, makes any warranty, express or implied, or assumes any legal liability or responsibility for the accuracy, completeness, or usefulness of any information, apparatus, product, or process disclosed, or represents that its use would not infringe privately owned rights. Reference herein to any specific commercial product, process, or service by trade name, trademark, manufacturer, or otherwise does not necessarily constitute or imply its endorsement, recommendation, or favoring by the United States Government or any agency thereof. The views and opinions of authors expressed herein do not necessarily state or reflect those of the United States Government or any agency thereof. 